\title{
As Novas Estratégias de Promoção do Brasil no Exterior: estudo de caso ${ }^{1}$
}

\section{The New Strategies of Brazil Promotion Abroad: case study}

\author{
Amalia Raquel Pérez-Nebra ${ }^{2}$ \\ Cleria Juliana Rosa ${ }^{3}$
}

\begin{abstract}
Resumo
Este estudo de caso tem como objetivo a análise das estratégias utilizadas pela EMBRATUR após suas novas atribuições ocorridas em 2003. O foco dessas estratégias é a modificação do posicionamento da atual imagem do Brasil no exterior. $O$ trabalho foi estruturado considerando Brasil como uma marca. Primeiro foi apresentada a base da organização, para posteriormente apresentar o cenário do turismo internacional e como o Brasil está inserido nele. Finalmente as estratégias adotadas pelo órgão e uma avaliação crítica de tais estratégias. É possível concluir acreditando que houve mudança quantitativa no quadro do turismo brasileiro; entretanto a mudança qualitativa não é possível inferir adequadamente com o pouco tempo de implementação. A marca-Brasil e suas estratégias foram avaliadas, e possibilidades de desenvolvimento são sugeridos ao final do trabalho, principalmente ligados à pesquisa e desenvolvimento.
\end{abstract}

Palavras-chave: EMBRATUR; estratégias; imagem; marca; imagem do destino turístico

\begin{abstract}
The goal of this case study is to analyze the strategies used by EMBRATUR after the new guidelines were established in 2003. The aim of these strategies was to modify the current positioning of the image that Brazil has abroad. This study was structured considering Brazil as a brand. First, we began by providing the background of the organization, then the scenery of international tourism and how Brazil is inserted in it. Finally the strategies adopted by the agency and a critical evaluation of such strategies. The conclusion suggests a perception of quantitative change in the scenario of the Brazilian tourism; although the qualitative rate was not possible to assess due to time constraints. Brand-Brazil and its strategies were assessed, and possibility of development was suggested at the end of the work, mainly on research and development.
\end{abstract}

Keywords: EMBRATUR; strategies; image; brand; tourism destination image

\footnotetext{
${ }^{1}$ As autoras agradecem a Amanda Fakih Leite e Kátia Macedo Dias pelos diversos apoios, ao Professor Carlos José Rodrigues da Silva pela colaboração na revisão e nos comentários valiosos para a elaboração e conclusão deste estudo de caso.

${ }^{2}$ Mestre e doutoranda em Psicologia Social e do Trabalho pela UnB. E-mail: amália@unb.br

${ }^{3}$ Estudante e bolsista de iniciação científica do Curso de Turismo do Centro Universitário de Brasília-UniCEUB. E-mail: cleriarosa@yahoo.com.br
} 


\section{Introdução}

Este de estudo de caso tem como objetivo apresentar uma avaliação das ações de um dos órgãos responsáveis pelo turismo no Brasil, o Instituto Brasileiro de Turismo - EMBRATUR, descrevendo suas ações no âmbito internacional para promoção do turismo brasileiro.

Sabe-se que o Brasil é principiante no que diz respeito a turismo internacional. Apresenta dificuldades que podem ser consideradas básicas como falta de infra-estrutura, treinamento e manutenção dos lugares turísticos. Recebe relativamente menos turistas internacionais do que todos os demais vizinhos na América Latina. A tabela a seguir contém dados de 2004 e demonstra a chegada relativa de turistas. Ou seja, em números absolutos o Brasil recebe mais turistas que outros países, mas considerando o seu tamanho e a densidade populacional, a porcentagem pode ser considerada pequena. Os dados de 2007 revelam que este número subiu para 3,5\% (EMBRATUR, 2004; IBGE, 2005).

Tabela 1: Relação entre chegada de turistas internacionais e população

\begin{tabular}{|l|l|l|l|}
\hline \multicolumn{1}{|c|}{ Países } & $\begin{array}{c}\text { Chegada de turistas } \\
\text { Internacionais }\end{array}$ & População & $\begin{array}{c}\text { Relação Turistas } \\
\text { Internacionais/ } \\
\text { População }\end{array}$ \\
\hline Uruguai & 1.756 .000 & 3.399 .237 & $51,66 \%$ \\
\hline México & 20.618 .000 & 106.202 .903 & $19,41 \%$ \\
\hline Chile & 1.785 .000 & 16.598 .074 & $10,75 \%$ \\
\hline Argentina & 3.353 .000 & 39.356 .215 & $8,52 \%$ \\
\hline Equador & 793.000 & 13.810 .000 & $5,74 \%$ \\
\hline Paraguai & 309.000 & 6.100 .000 & $5,07 \%$ \\
\hline Bolívia & 405.000 & 9.627 .269 & $4,21 \%$ \\
\hline Peru & 1.203 .000 & 28.674 .757 & $4,20 \%$ \\
\hline Brasil & 4.794 .000 & 183.987 .291 & $2,61 \%$ \\
\hline Venezuela & 492.000 & 27.483 .200 & $1,79 \%$ \\
\hline Colômbia & 791.000 & 44.379 .598 & $1,78 \%$ \\
\hline
\end{tabular}

Fonte: EMBRATUR (2004); Indec (2004); IBGE (2005)

Este quadro se modificou com as novas ações, tanto em nível nacional quanto internacional, e o que será apresentado é uma avaliação das estratégias utilizadas pelo órgão oficial de divulgação do Brasil.

Para alcançar esse objetivo os seguintes tópicos são abordados: um breve histórico sobre a organização e o turismo internacional no Brasil, para contextualizar a situação em que se encontrava o Brasil antes das ações, as características do mercado de turismo e, 
especificamente, das questões relacionadas à marca, foco principal do trabalho. Finalmente, se busca fazer uma avaliação das estratégias adotadas pela organização e apresentar algumas considerações.

\section{Histórico da Organização}

A EMBRATUR foi criada a partir do decreto-lei no 55 em 18 de novembro de 1966, tendo como responsabilidade gerenciar tudo que envolvia, ou estivesse relacionado com o Turismo no Brasil e suas políticas públicas junto ao Ministério do Esporte e Turismo. Em 1992 a sede da EMBRATUR foi transferida do Rio de Janeiro para Brasília, deixando de ser uma empresa pública mista para tornar-se uma autarquia, de acordo com a lei n. 8.181/1991. Nessa fase, a empresa era dividida em três diretorias: Administração, Economia e Fomento, e Marketing.

Porém, em 28 de maio de 2003, com a lei no 10.683, cria-se o Ministério do Turismo, tornando-se responsável pela divulgação e aprimoramento do turismo interno, o que refletiu em um processo de reestruturação do foco e das responsabilidades da EMBRATUR no fomento do turismo nacional, transferindo com o decreto $\mathrm{n}^{\circ}$ 4.898/2003, suas competências para o Ministério do Turismo, relativas a cadastrar, fiscalizar, classificar empresas prestadoras de serviços turísticos hotéis, agências de viagens, organizadoras de eventos, transportadoras turísticas e guias de turismo, entre outros; do Programa Nacional de Municipalização do Turismo (PNMT); projetos de segmentação; eventos e promoção nacional; infra-estrutura e sinalização. Assim, o Instituto fica encarregado pela promoção e comercialização do destino Brasil no exterior.

\section{Características da Empresa}

É organização estatal sem fins lucrativos, possuindo 264 funcionários, incluindo o quadro de estagiários. Sua estrutura organizacional é vertical e está dividida em cinco departamentos: Administração e Finanças; Estudos e Pesquisas; Marketing; Turismo de Lazer e Incentivo e Turismo de Negócios e Eventos. Além disso, faz parte da estrutura organizacional do Ministério do Turismo, pois responde ao Ministro.

Os dirigentes são indicados política e tecnicamente para exercerem os seus cargos. Alguns assumem cargos de confiança, outros são contratos terceirizados por meio de licitações de serviços. Assim, o quadro é diverso, o que pode dificultar alguns trabalhos. As instalações físicas, 
assim como os equipamentos, estão sendo renovados. No seu processo decisório predomina a autocracia e verticalidade, assim os dirigentes são cobrados pelos processos decisórios.

Por não possuir canais de financiamento, trabalha com Convênios e Parcerias firmados com órgãos, associações e instituições tais como a Organização das Nações Unidas para Educação Ciência e Cultura (UNESCO), o Serviço Brasileiro de Apoio às Micro e Pequenas Empresas (SEBRAE), a Fundação Comissão de Turismo Integrado do Nordeste, o Rio Convention Bureau, a Associação Brasileira das Operadoras de Turismo (BRAZTOA) e a Fundação Getúlio Vargas (FGV).

No que se refere às fontes de crédito, a importância é disponibilizada pelo benefício que o Governo Federal disponibiliza anualmente, para que sejam viabilizadas as ações previstas pela Empresa. A EMBRATUR com seu insuficiente quadro de funcionários para todas as atividades que realiza, utiliza serviços de outras empresas para o desenvolvimento de ações maiores, portanto, depende de licitação, o que normalmente deixa o trabalho moroso e lento quando comparado às características do setor em que atua.

\section{Turismo Internacional}

Ressalta-se a importância do segmento de turismo no mundo, que em 2003 gerou, de acordo com a Organização Mundial de Turismo (OMT), uma receita derivada do turismo internacional de US\$ 514 bilhões, aproximadamente 8\% superior ao ano anterior, que foi de US\$ 474 bilhões. Esse segmento destaca-se como sendo um dos que mais crescem na economia mundial. No Brasil é um grande gerador de emprego, fator de grande interesse: considerando que em média 20\% da população está desempregada (IBGE, 2005).

Com o cenário atual da importância do turismo no Brasil, a tabela a seguir (Tabela 2) mostra o fluxo turístico mundial e o brasileiro. Internacionalmente, no ano de 2003, esse fluxo foi de 694,0 milhões de pessoas, o que indica um pequeno decréscimo com relação ao ano de 2002 de 1,2\% (em 2002, alcançou 702,6 milhões). Entretanto, a contribuição do Brasil no cenário internacional é ainda relativamente modesta, como apresentado anteriormente (6,4 milhões em 2007 segundo a EMBRATUR S/Da). Quando se pondera que o Brasil é o quinto país do mundo em extensão territorial e a décima terceira economia mundial assim, sua participação no mercado turístico fica evidentemente pouco significativa (THOMAS, S/D). 
Tabela 02: Principais países receptores de turistas 2000/2003.

\begin{tabular}{|l|l|l|l|l|}
\hline Países & $\mathbf{2 0 0 0}$ & $\mathbf{2 0 0 1}$ & $\mathbf{2 0 0 2}$ & $\mathbf{2 0 0 3}$ \\
\hline França & $75,6^{4}$ & 76,5 & 77,0 & 75,0 \\
\hline Espanha & 47,9 & 49,5 & 52,3 & 52,5 \\
\hline Estados Unidos & 50,9 & 45,5 & 41,9 & 40,4 \\
\hline Itália & 41,2 & 39,1 & 39,8 & 39,6 \\
\hline China & 31,2 & 33,2 & 36,8 & 33,0 \\
\hline Reino Unido & 25,2 & 22,8 & 24,2 & 24,8 \\
\hline Áustria & 18,0 & 18,2 & 18,6 & 19,1 \\
\hline México & 20,6 & 19,8 & 19,7 & 18,7 \\
\hline Alemanha & 19,0 & 17,9 & 18,0 & 18,4 \\
\hline Canadá & 19,7 & 19,7 & 20,1 & 17,5 \\
\hline$\ldots$ & & & & \\
\hline Brasil & 5,3 & 4,8 & 3,8 & 4,1 \\
\hline Outros & 332,7 & 337,1 & 350,4 & 350,9 \\
\hline Total & 687,3 & 684,1 & 702,6 & 694,0 \\
\hline
\end{tabular}

Fonte: BRASIL - Ministério do Turismo (S/D)

O fluxo turístico do Brasil em relação ao mundo pode ser considerado tímido, mas esse quadro também se repete quando se compara o país com a América Latina, onde os países vizinhos recebem relativamente mais turistas do que o Brasil. Em termos gerais, a contribuição tem crescido a cada ano, mas comparando o tamanho do Brasil com os demais países da América Latina, e sua proximidade e importância econômica, tem potencial para apresentar um número ainda superior, como pode ser visto na tabela abaixo (Tabela 03).

Tabela 03: Participação do Brasil no Fluxo Turístico Mundial 1994 / 2003.

\begin{tabular}{|c|c|c|c|c|c|c|}
\hline \multirow{2}{*}{ Ano } & \multicolumn{7}{|c|}{$\begin{array}{c}\text { No Mundo } \\
\text { (Em } \\
\text { milhões) }\end{array}$} & $\begin{array}{c}\text { Na América } \\
\text { do Sul (em } \\
\text { milhões) }\end{array}$ & $\begin{array}{c}\text { Participação } \\
\text { \%) da América } \\
\text { do Sul no } \\
\text { Mundo }\end{array}$ & $\begin{array}{c}\text { No Brasil (Em } \\
\text { milhões) }\end{array}$ & $\begin{array}{c}\text { Participação (\%) } \\
\text { do Brasil na } \\
\text { América do Sul }\end{array}$ & $\begin{array}{c}\text { Participação (\%) } \\
\text { do Brasil no } \\
\text { Mundo }\end{array}$ \\
\hline 1994 & 550,5 & 10,8 & 1,96 & 1,85 & 17,16 & 0,34 \\
\hline 1995 & 565,5 & 11,8 & 2,09 & 1,99 & 16,88 & 0,35 \\
\hline 1996 & 596,5 & 12,9 & 2,16 & 2,67 & 20,66 & 0,45 \\
\hline 1997 & 610,8 & 13,5 & 2,21 & 2,85 & 21,11 & 0,47 \\
\hline 1998 & 626,6 & 15,5 & 2,47 & 4,82 & 31,08 & 0,77 \\
\hline 1999 & 650,2 & 15,1 & 2,32 & 5,11 & 33,82 & 0,79 \\
\hline 2000 & 687,3 & 15,2 & 2,21 & 5,31 & 34,96 & 0,77 \\
\hline 2001 & 684,1 & 14,4 & 2,10 & 4,77 & 33,14 & 0,70 \\
\hline 2002 & 702,6 & 12,5 & 1,78 & 3,78 & 30,27 & 0,54 \\
\hline 2003 & 694,0 & 14,2 & 2,05 & 4,09 & 28,81 & 0,59 \\
\hline
\end{tabular}

Fonte: BRASIL - Ministério do Turismo (S/D)

\footnotetext{
${ }^{4}$ Em milhões. Fonte: OMT, DPF e EMBRATUR
} 
Mesmo com sua visibilidade no mapa-múndi e sendo a maior economia latino-americana, o Brasil não é uma opção de destino turístico para a maioria das pessoas fora de suas fronteiras e do continente. Uma das principais razões para o número reduzido de turistas estrangeiros no Brasil é a imagem que o país possui no exterior. Autores como Bignami (2002), Leal (2004), e Rezende-Parker, Morrison e Ismail (2003) afirmam que, quando lembrado, é associado às imagens do carnaval, mulheres de sexo fácil, malandragem e praias paradisíacas. Pouco se sabe sobre o Brasil, mesmo os residentes no país conhecem pouco sobre sua economia, produção, arrecadação e outros aspectos. Para um país diverso como é o Brasil, estar na posição que ocupa no turismo internacional pode ser motivo de vergonha.

Além disso, o Brasil é lembrado espontaneamente pela imprensa internacional como cenário de violência e, portanto, inseguro para turistas, bem como é comum a apresentação de notas em guias para os turistas internacionais com sugestões para turistas do que levar ou deixar no hotel (BIGNAMI, 2002). Além disso, a imprensa nacional parece alardear mais violência do que o necessário. Com este quadro, não é de se estranhar números baixos nas estatísticas do turismo internacional.

É relevante destacar também que as receitas arrecadadas com o ingresso de turistas no país no período 2003 e 2004 apresentaram um crescimento de 29,92\%, uma alta porcentagem em relação ao cenário internacional, porém acanhada em termos absolutos.

Pode-se compreender por que a partir da situação apresentada, os consumidores de turismo ainda não escolhem o Brasil como destino turístico. Outros fatores podem ser apontados como obstáculos ao crescimento do turismo internacional no Brasil, como por exemplo:

- Carência de infra-estrutura completa de serviços turísticos. Implica em ausência de uma ampla e adequada infra-estrutura hoteleira, inadequação dos serviços prestados por agências de viagens e operadoras de turismo e pouca oferta de serviços complementares aos de hospedagem e transporte, principalmente no tocante a cultura. Além de falta de treinamento adequado e de cuidado com a população autóctone (MARIANI, 2002; PAIVA, 1995).

- Nível de segurança aos turistas ainda insatisfatório. Intensificação da criminalidade nos grandes centros urbanos e de comentários ainda freqüentes e negativos sobre o Brasil (BIGNAMI, 2002); 
- Carência de uma adequada infra-estrutura de transporte aos turistas, restringindo sua flexibilidade de circulação no país (PAIVA, 1995).

De acordo com a última pesquisa realizada pela EMBRATUR (2004), constatou-se que o grau de insatisfação de turistas estrangeiros em visita ao Brasil é decorrente dos seguintes fatores: falta de sinalização turística (10,3\%), limpeza pública deficiente (10,1\%) e segurança pública (9,3\%). Ressalta-se que este número aparentemente pequeno pode dar-se pelo procedimento e instrumento de coleta de dados escolhido pela EMBRATUR. Assim, é possível notar que a sinalização precária ou inexistente é percebida como um pouco pior pelo turista do que a segurança pública. Vale lembrar que sinalização precária não se trata apenas de placas, mas também de mapas em diversos idiomas, guias de turismo, sinalização urbana de trens, metrôs, ônibus, paradas entre outros que estejam disponíveis, em boas condições e fieis.

\section{Características do Mercado em que Atua: e a Marca Brasil?}

O mercado pode ser entendido como o estabelecimento de uma relação entre a oferta e a demanda de bens, serviços e capitais. Portanto, todas as pessoas e empresas que oferecem ou demandam bens, serviços e capitais determinam o surgimento organizado e as condições dessa troca, surgindo então, mercados específicos, que formam a estrutura do comércio nacional e internacional (BENI, 2001). No caso do Turismo que é considerado fundamentalmente um serviço, sendo também um dos mais antigos mercados do mundo, a oferta e demanda de serviço já poderia estar mais bem estabelecida e estruturada dada sua história (RUSCHMANN, 1990).

Beni (2001, p. 146) afirma que o mercado é um sistema impessoal, descentralizado e muito sensível às mudanças nas condições dos elementos que o integram, de modo que é também de rápida reação e adaptável a cada situação, resolvendo suas questões econômicas em relação à troca através do preço. Assim, o turismo enquadra-se perfeitamente nesta descrição, vez que os elementos que o integram apresentam atores diversos e com diferentes qualidades oferecidas e praticando preços muitas vezes incompatíveis entre si (ANDRADE, 2000).

Os produtos turísticos são heterogêneos, característica de seu mercado. Cada empresa vende um produto que se traduz como diferenciado dos demais. Assim, não existem dois hotéis iguais e nem instalados no mesmo lugar, o que um oferece, o outro não o fará exatamente da mesma maneira; espera-se que o roteiro turístico produzido e comercializado por uma 
operadora seja único, assim como a qualidade oferecida por uma companhia aérea não será a mesma que aquela oferecida pelo hotel no destino (BENI, 2001, p. 149-150).

Silva (2005, p. 81) aponta outro fator importante atuante no mercado que são as ações de marketing direcionadas aos lugares turísticos a fim de avaliar as novas tendências, oportunidades e ameaças ao negócio. Tais atividades são importantes pelo grande esforço e competitividade entre os lugares turísticos em cada vez mais atrair um número maior de turistas, prolongando sua permanência no local e aumentando seus gastos, além da melhoria constante da qualidade dos serviços e equipamentos ofertados.

Outros aspectos a serem levados em consideração no marketing são os avanços tecnológicos (SILVA, 2005, p. 82). Esse avanço tecnológico vem transformando totalmente o mercado internacional. A Internet acelera o fluxo e o acesso a informações turísticas, além de proporcionar maior comodidade ao cliente, que agora pode comprar sua passagem aérea ou um pacote turístico on-line. As instabilidades ambientais e políticas dos lugares também são aspectos importantes que devem ser observados nas estratégias de marketing a fim de que se criem ações para que esses problemas possam ser solucionados e os destinos não sejam severamente prejudicados (SILVA, 2005).

Considerando, então, que o turismo atende a mercados diferentes e extremamente competitivos e muitas vezes um planejamento de marketing adequado não é realizado, é preciso conhecer o resultado, ou seja, como o turismo internacional é divulgado fora do Brasil, o papel da imagem do destino e da marca.

Já se sabe da importância da segmentação de mercado para o turismo e para o turista. Mas para que um destino, produto ou serviço turístico se consolide no mercado, e se considere entre um dos possíveis destinos de escolha dentre as várias opções dadas ao turista, é necessário o desenvolvimento de uma marca, em que o consumidor possa confiar e, aliado a isso, a construção de uma imagem de qualidade em relação ao destino promovido.

A imagem de marca é formada pelo conjunto de crenças e atributos que os consumidores reconhecem e conectam com o nome de uma marca específica, e é uma das bases do qual estão as suas decisões (KOTLER; BOWEN e MARKENS, 1999). Nesse sentido, a imagem de uma marca será o resultado da interligação entre as estruturas mentais do consumidor e o leque de ações de marketing destinadas a capitalizar o potencial contido no conhecimento da marca, gerando, assim, valor (RUÃO e FARHANGMER, 2000). 
Para Kotler e Gertner (2002), mais do que um nome, a marca gera uma série de valores e conceitos, tornando-se um símbolo, em busca de credibilidade, legitimidade e fidelização do cliente.

A imagem e o valor da marca são associados a empresas, produtos e serviços, diferenciandose da imagem do destino, que de acordo com Crompton (1979) define imagens de locais de férias como a soma de crenças, idéias e impressões que uma pessoa tem de um local de destino. No que diz respeito às dimensões da imagem do destino, Mayo (1975, apud ROSS, 2001), apresenta que o local ideal para a maioria dos turistas deve oferecer muito em termos de cenário; não deve ser congestionado nem com pessoas, nem com indústrias, embora a densidade de sua população também não deva ser pequena demais. Além disso, o destino deve ter um clima muito agradável. Mas, apesar de todos os aspectos citados anteriormente, Hoffman e Low (1978, apud ROSS, 2001) descobriram que a variável mais importante em qualquer decisão do visitante em retornar ao destino visitado é a imagem que ele tem da cordialidade da população local. Desse modo, a decisão de retornar não é tão influenciada pelas imagens das comodidades e atributos da região, nem da distância do seu local de origem, mas pela cordialidade da população local na visão do turista.

Com base em McKay e Fesenmaier (1970, apud ROSS, 2001) é possível definir que a formação da imagem do local de destino é uma combinação de fatores individuais informação e aprendizagem, e de fatores publicitários, que são responsáveis pelos aspectos visuais na promoção do destino, isto é, atração, exotismo e estrutura (ROSS, 2001), assim como de fatores de vivência com o serviço (MOWEN e MINOR, 2003; TYBOUT e STERNTHAL, 2001).

A imagem turística do Brasil no exterior, de acordo com Bignami (2002), é uma imagem altamente estereotipada, centrada em alguns poucos eventos culturais nacionais, algumas cidades principais e determinadas características que qualificam o povo brasileiro. A imagem atrativa que tenta vender o Brasil para turistas é limitada e circunscrita no discurso da imprensa ou no parco conhecimento histórico que se tem a respeito da nação. Pouco se fez em termos de publicidade ou promoção visando alterar tal imagem. O Brasil pode ser considerado uma terra de contrastes, um paraíso e um inferno contemporaneamente. Uma terra de grandes riquezas e pobrezas. É selvagem, sensual e místico. Ou um país onde, conforme Pérez-Nebra (2005), a cultura é rica, mas o turista não tem acesso a ela.

Além dessa imagem que se apresenta como atrativa, divulgam-se também, segundo Bignami (2002), os problemas sociais do país, compondo uma imagem repulsiva. Essa imagem impede 
a chegada de novos turistas ao Brasil; ela não se compõe somente do noticiário sangrento publicado pela imprensa cotidiana. Encontram-se vestígios da mesma imagem nos discursos que tentam promover o turismo, sob forma de conselhos ao turista, falando sobre o que evitar, onde não transitar, o que levar ou deixar no quarto do hotel etc. Desse modo, essas informações tendem a desmotivar o turista, compondo o imaginário dos medos e receios dos viajantes.

Limitar a promoção turística à somente um ou dois aspectos da nossa vasta realidade cultural e natural, significa também limitar segmentos de mercado que poderiam ser atraídos por outros aspectos da oferta turística nacional, como por exemplo, vender apenas o Carnaval, como se mais nada existisse em termos de manifestações folclóricas no país (BIGNAMI, 2002). Outro aspecto, de acordo com Pérez-Nebra (2005), é que o turista potencial tem a imagem de que o Brasil é folclórico em todos os lugares, como exemplo, ele chegará no aeroporto de São Paulo e verá mulatas de carnaval e baianas no saguão, e sai decepcionado com este aspecto. Por outro lado, quem já esteve no Brasil sai satisfeito com as atividades de entretenimento e lazer que encontra, pois não imaginava que houvesse tantas.

O Brasil, aparentemente, não usa de forma correta os recursos de que dispõe. Somente a promoção do atrativo não é suficiente para que o torne importante ao mercado. No Brasil falta estrutura, mão-de-obra qualificada e maior acesso ao produto por parte do turista que o consome, e a comunidade local poderia, e deveria, se beneficiar economicamente com o turismo, mas acaba sendo massacrada por grandes redes e pela exploração imobiliária (MARIANI, 2002; PAIVA, 1995). Assim, sua marca institucional é fraca porque o país não pode oferecer qualidade, mas também não quer abaixar seu preço ao que seria o adequado, pois economicamente não é viável.

A marca institucional para uma organização é um bem tão precioso quanto seu produto ou serviço, pois define, identifica e dá a devida credibilidade ao produto. Levando em conta que a marca é virtual e abstrata, com a mensagem se realizando na mente do observador, ela se torna essencial na identificação, reconhecimento e aprovação de qualquer produto ao qual esteja agregado. A utilização correta da Marca Institucional reafirma a imagem de organização, solidez e confiança à instituição (BERKOWITZ; KERIN e RUDELIUS, 2004).

A marca-país se forma a partir do que as pessoas percebem do país diretamente ou via terceiros, num processo de prova e reforço em áreas como política exterior, ajuda, comércio, discurso público, cultura, turismo e marcas (CIAFFONE e AZEDO, 2004). Vale a ressalva que marca-país é diferente de imagem do destino. A primeira diz respeito a produtos que têm 
no país uma referência de bons produtos. Já a segunda indica a imagem que a pessoa tem sobre o destino turístico daquele país (PÉREZ-NEBRA, 2005).

Ela está acima da qualidade de produção nacional, das atrações turísticas, do custo da mãode-obra local, da capacidade instalada da indústria e mesmo dos bens culturais do país. A marca passa a ser um valioso ativo de mercado. É valiosa demais para ser mal administrada, pois, se gerenciada com organização, cooperação e comprometimento dos setores envolvidos, a marca-país pode agregar valor às importações, atrair investimentos externos e desenvolver um novo destino para o turismo internacional (ATHIA, 2004). Entretanto, no Brasil, é um patrimônio que não vem sendo cuidado de forma adequada.

O fato é que várias pesquisas constatam que simples informações sobre o país de origem influenciam no comportamento dos consumidores. No entanto, é válido ressaltar que a marcapaís não é responsabilidade somente do governo. Projetar e implementar uma estratégia de marca envolve tantos aspectos que isso só podem ser alcançados com a participação conjunta dos setores público e privado. Todas as empresas, comunidades e pessoas envolvidas nesse processo de promoção precisam entender de marca-país e saber fomentá-la para atrair investidores e consumidores internacionais (BERKOWITZ; KERIN e RUDELIUS, 2004).

A empresa no Brasil, de maneira institucionalizada, responsável pela divulgação da marcaBrasil e também da imagem do destino turístico do Brasil no exterior é o Instituto Brasileiro de Turismo - EMBRATUR, e suas estratégias serão apresentadas na próxima seção.

\section{Estratégia Adotada pela EMBRATUR}

A partir do governo do Presidente Luiz Inácio Lula da Silva, no ano de 2003, algumas alterações nas funções de cada órgão relacionado ao Turismo foram feitas. Desta maneira, o Ministério do Turismo assumiu as funções sobre o turismo interno e a EMBRATUR, conforme mencionado anteriormente, ficou responsável pela promoção do Brasil no exterior.

Partindo do pressuposto de que o Brasil possuía uma demanda turística internacional significativa e que a nova função da EMBRATUR era a de aumentar o número de turistas provenientes de outros países e gerar um crescimento nas divisas, foram necessárias algumas providências e ações emergenciais. Após algumas análises realizadas pela EMBRATUR, verificou-se a necessidade de elaborar uma vasta pesquisa com os turistas estrangeiros para conhecer as expectativas e os principais argumentos de persuasão a serem posteriormente 
utilizados. A Chias Marketing, empresa sediada na Espanha, foi a consultoria contratada para desempenhar este papel por meio de licitação.

Porém, uma pesquisa de marketing demanda tempo para a obtenção de dados suficientes para a elaboração de uma comunicação visual de qualidade e com a eficiência necessária para aumentar a demanda turística. Não obstante, como todas as ações necessitam da aprovação do Governo Federal, os trâmites legais também acarretam a demora do processo.

O que se fez enquanto o estudo não estava concluído foi a criação de um material de apoio baseado apenas em alguns dados de conhecimento geral. Assim, foi solicitada à agência responsável a confecção de uma comunicação visual que possibilitasse a visualização nova do Brasil. A agência que criou o conceito provisório foi a Artplan, sediada em Brasília. Algumas ações foram definidas logo no inicio como a exploração dos 11 segmentos: Sol-e-Mar, Ecoturismo, Aventura, Golfe, Pesca Desportiva, Mergulho, Negócios e Eventos, Incentivo, Cidade patrimônio, Festas Populares e Resorts.

Todavia, não era possível esperar os estudos ficarem prontos para a elaboração de um material, mesmo que esse não fosse o mais correto. Realizou-se assim uma comunicação 'tampão', como apresenta Dias (2005). A comunicação mesmo que sem uma pesquisa profunda de qualidade foi realizada. Os conceitos de brasilidade conhecidos no exterior eram as cores da seleção brasileira de futebol, verde-amarelo, a diversidade de paisagens e a cultura muito singular. Sendo assim, essas características foram evidenciadas na comunicação (DIAS, 2005).

Na Figuras 1, abaixo, as cores verde e amarelo foram utilizadas juntamente com a fonte desenvolvida especialmente para a EMBRATUR. O alfabeto teve como características uma fonte exclusiva. Tentou-se, com isso, criar uma identidade visual ainda mais forte. Como nas figuras baixo:

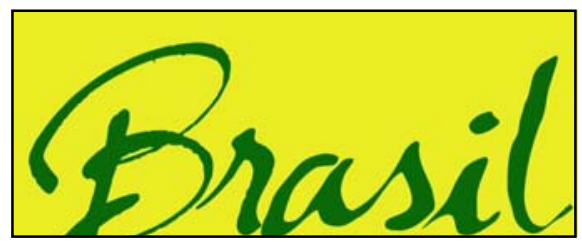

Figura 1 - Logomarca Desenvolvida para a Comunicação Visual 
Todas as peças, a partir da elaboração dessa identidade visual, passaram a adotar as novas fontes, e por existirem as regras de utilização, a marca poderia mudar de cor seguindo a padronagem determinada anteriormente pela agência. Verificou-se que, mesmo com mudança nas cores, é possível caracterizar a peça como uma promoção brasileira pela tipologia. E acima de tudo, não era possível colocar tal fonte em qualquer outro material publicitário, passando a ser de uso exclusivo da EMBRATUR no exterior (DIAS, 2005). Essa identificação é muito importante, pois avaliza as ações do Órgão governamental.

Entretanto, nem tudo deu certo com a tipologia personalizada. Segundo Bittencourt (2004 apud DIAS, 2005), percebeu-se que a legibilidade da fonte era pequena, não foram realizados os pré-testes em todos os idiomas e para textos muito extensos ocorria confusão na leitura, por isso decidiu-se optar por colocar apenas o nome Brasil com esta fonte.

Outro fator relevante foi o de destacar as belezas que o país possui de forma clara e com uma mensagem positiva. A alternativa encontrada para destacar essa característica de diversidade foi a elaboração do conceito de mosaico. Partindo do uso do mosaico, a colocação de várias imagens juntas foi a idéia desenvolvida para explorar a diversidade brasileira de forma clara e objetiva, mostrando os destinos, as pessoas e a cultura do país (DIAS, 2005).

Essa campanha tampão vigorou até 2005, para dar lugar à Marca-Brasil, que surgiu a partir da criação do Plano Aquarela e as demais estratégias previstas no Plano Nacional do Turismo (PNT), desenvolvido pelo Governo Federal, por meio do Ministério do Turismo.

Pela primeira vez o Governo Federal contemplou o turismo como uma das prioridades de ação e desenvolvimento, não somente do fluxo de turistas e aumento de divisas, mas também do aumento da qualidade de produtos, serviços e mão-de-obra envolvida no setor. Com essa finalidade desenvolveu-se o Plano Nacional do Turismo, ações como os Escritórios Brasileiros de Turismo fora do Brasil (EBTs), o projeto “Caravana Brasil” (levar operadores nacionais e internacionais para conhecer os destinos brasileiros in loco), Press-trips (Presstrip eram viagens subsidiadas para a imprensa internacional com o objetivo de divulgar o Brasil) e a Marca Brasil, que terá uma seção exclusiva, devido a sua importância.

Para isso foi criado o Plano Nacional de Turismo (BRASIL - Ministério do Turismo, 2003, p.23), em que foram estabelecidas as seguintes metas até 2007:

- Criar condições para gerar 1.200.000 novos empregos e ocupações;

- Aumentar para 9 milhões (Meta Desafio) o número de turistas estrangeiros no Brasil;

- Gerar 8 bilhões de dólares em divisas; 
- Aumentar para 65 milhões a chegada de passageiros nos vôos domésticos;

- Ampliar a oferta turística brasileira, desenvolvendo no mínimo três produtos de qualidade em cada Estado da Federação e Distrito Federal.

A promoção e apoio à comercialização dos produtos turísticos brasileiros é feita a partir de diversas ações. Entre elas: participação em feiras internacionais de turismo (com a ampliação da agenda já existente, focando não somente em turismo de lazer, mas também em turismo de negócios e eventos); realização e participação em promoções (parceria com empresas brasileiras em lançamentos de produtos e eventos); ações de oportunidade (participação em grandes eventos brasileiros no exterior, como oportunidade de promoção do turismo); captação e promoção de eventos; e promoção de eventos internacionais (EMBAIXADA DO BRASIL, 2004).

Para o alcance das metas anteriormente citadas, foram implantados, com um investimento de R\$ 3,9 milhões, em 2004, os Escritórios Brasileiros de Turismo (EBTs) em Berlim (Alemanha), Londres (Inglaterra) e Roma (Itália). Estavam previstos também escritórios em Madri (Espanha) e outros dois nos Estados Unidos. Já funcionam os de Lisboa (Portugal), Paris (França), Nova York (EUA), além de um na América do Sul, sediado em Brasília (para atender América do sul e embaixadas). Este último atua em nove países (Argentina, Paraguai, Uruguai, Chile, Peru, Bolívia, Venezuela, Equador e Colômbia), por meio dos SECOMs (Setores de Promoção Comercial) das Embaixadas Brasileiras (EMBRATUR, S/Db).

Os EBTs são unidades avançadas de promoção, marketing e apoio à comercialização dos produtos, serviços e destinos turísticos brasileiros no exterior. Para cada um estão previstas as pesquisas do perfil do consumidor e das preferências do mercado, a formação de uma base de dados da cadeia produtiva emissiva e a identificação de operadores para saídas da "Caravana Brasil”, além da coordenação de Press-trips e identificação e análise de benchmarking.

Essas unidades também têm a função de apoio à captação de eventos internacionais para o Brasil, assim como a sua promoção. Participarão de feiras da “Agenda de Promoção Comercial” e realizarão ações promocionais e seminários voltados ao negócio e agentes econômicos envolvidos.

O objetivo dos EBTs é consolidar a imagem do país como um destino turístico competitivo no exterior. Os profissionais são responsáveis por promover o destino Brasil de maneira específica em cada país, organizando reuniões e seminários para agentes econômicos e 
profissionais do setor, fomentando o turismo de negócios e eventos e apoiando a captação de eventos (BUSINESS GUIDE, 2004).

Alinhado com as estratégias de promoção do Brasil no exterior o Projeto Caravana Brasil foi criado em 2003. A finalidade é aproximar os agentes envolvidos na cadeia produtiva do turismo para que juntos possam trocar idéias de como fomentar cada produto e destino e ser também uma ferramenta de apoio à comercialização do setor.

Esta nova estratégia foi adotada a fim de intensificar o turismo interno do Brasil. Seu desenvolvimento e aplicação têm como premissa a diversificação dos produtos brasileiros, hoje comercializados no mercado internacional, acrescentando novos produtos e fortalecendo os outros já comercializados. Aproveita ainda para aproximar os operadores turísticos estrangeiros dos fornecedores de produtos turísticos do Brasil, ampliando as possibilidades de comercialização, com visitas aos novos produtos, demonstrando suas potencialidades.

A escolha dos destinos a serem visitados é direcionada a produtos turísticos consolidados, ou seja, que ao serem visitados pelas caravanas, oferecem aos clientes além do conhecimento da localidade e análise de suas potencialidades, a possibilidade de interação dos operadores com fornecedores turísticos locais.

Além do Projeto Caravana Brasil, a Gerência de Apoio à Comercialização, subordinada à Diretoria de Turismo de Lazer e Incentivo, lançou em 2005, o Press-trips Brasil. O Presstrips Brasil consiste na vinda de jornalistas estrangeiros para que possam conhecer no Brasil os produtos e destinos brasileiros, gerando matérias em seus veículos e divulgando o país no exterior.

Essas ações possibilitarão uma maior exposição dos destinos e produtos brasileiros para diferentes públicos, com baixo custo. Os critérios de seleção dos participantes serão rigorosos, levando em consideração a abrangência do veículo, público-alvo, pauta prevista etc.

É importante evidenciar que, com o comprometimento de todos, o reflexo deste esforço já está sendo exposto pela mídia, com resultados bastante positivos para o incremento do fluxo de turistas internacionais no Brasil. Todos estes projetos são apoiados por uma imagem de marca que foi desenvolvida para o Brasil, chamada marca-país, que é utilizada apenas para os produtos e para o turismo internacional. 


\subsection{A Marca Brasil}

O primeiro resultado direto do Plano Aquarela, a Marca Brasil passou a representar e promover o turismo brasileiro, assim como os principais atributos de exportação do País no exterior (Figura 2). O símbolo está sendo incorporado a todo o programa de promoção, divulgação e apoio à comercialização dos produtos, serviços e destinos turísticos brasileiros no mercado internacional. Foram investidos R 4 milhões no processo de criação da marca, que envolveu pesquisas com empresas e estrangeiros que visitaram o Brasil, além de potenciais turistas para o país. Foram ouvidos 190 operadores turísticos de 18 mercados, 1.200 turistas que visitaram o país e 5.000 pessoas de 18 países que nunca estiveram no Brasil (FORTES, 2005).

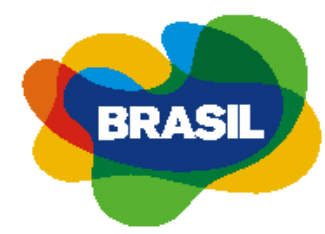

Figura 2 - Marca Brasil

O novo símbolo aponta como os estrangeiros enxergam o Brasil: multicolorido. As cores eventualmente se sobrepõem. O verde é associado às florestas; o azul ao céu e às águas; o amarelo ao sol e a luminosidade; o vermelho e o laranja às festas populares; e o branco às manifestações religiosas e a paz. A Marca Brasil foi construída tendo como referência pontos como alegria, sinuosidade, luminosidade e modernidade (FARKAS, S/D).

\section{Resultado da Estratégia}

Como resultados parciais da estratégia adotada pela EMBRATUR pode-se salientar que o turismo no Brasil vem crescendo acima de 15\%, e a média de crescimento mundial tem sido de 10\% (EM QUESTÃO, n. 353, 2005). Atualmente a EMBRATUR tem entrado em novos mercados com maiores recursos financeiros, além de uma estratégia já consolidada com os EBTs, que já estavam funcionando nos grandes emissores de turismo para o Brasil e agora estarão sendo implantados em outros países.

Ainda que o turismo no Brasil esteja crescendo, sua fatia de mercado permanece pequena. Caso ela alcançasse a meta pretendida utilizando as estratégias descritas anteriormente, em 
2007, de 9 milhões de turistas, e considerando uma estabilização do número de turistas internacionais, chegar-se-ia na casa de 1,2\% de participação da fatia de mercado, o que implica no dobro do que o Brasil representava em 2003, mas ainda com muita possibilidade de crescimento. Tardará ainda muitos anos para que esta estratégia repercuta significativamente no ranking do Brasil como destino internacional do turismo. Mesmo com esse crescimento, o país ainda estará longe dos 10 primeiros colocados, que possuem praticamente o dobro de chegadas de turistas que o Brasil pretende para 2007. Como a Tabela 2 mostra, o Canadá, que está em 10- lugar no ranking, recebeu em 2003 17,5 milhões de turistas, o Brasil recebeu no mesmo ano apenas 4,1 milhões, e pretende para 20079 milhões, o que significa dobrar o que teve em 2003, entretanto, estará praticamente na metade do que possui hoje o $10^{\circ}$ colocado.

A melhoria da imagem e a consolidação de estratégias, bem como uma definição mais clara das atribuições representadas pela EMBRATUR e pelo Ministério do Turismo auxiliaram sobremaneira a que o foco da Instituição ficasse, finalmente, voltado apenas ao turismo internacional, o que viabilizou que os esforços ficassem concentrados em uma única direção. Espera-se que a estratégia apresente resultados positivos. Por outro lado, sabe-se que são insuficientes para alavancar o turismo internacional. Outras ações e políticas precisam ser tomadas.

Além disso, os níveis de satisfação dos turistas têm crescido em duas direções opostas. A EMBRATUR na sua pesquisa com os turistas internacionais pergunta sobre a superação das expectativas dos mesmos com relação ao turismo. A escala tem dois extremos, de superação da expectativa de um lado, decepção de outro e no meio o ponto neutro. Considerando os anos de 2000 a 2003, houve um crescimento alto no que diz respeito à superação das expectativas (de 17,2\% para 31,7\% na no extremo de superação), por outro lado, também cresceu a decepção dos turistas (de 1,2 para 2,2 no outro extremo) (EMBRATUR, 2004). Apesar da decepção ser ainda muito pequena em termos numéricos, ela também apresenta um crescente que deve ser considerado.

\section{Análise da Estratégia}

A EMBRATUR, com o Plano Aquarela, foco deste estudo de caso, pode ser avaliado como um caso de sucesso, ainda mais considerando o cenário em que estava inserido. Ao analisar a estratégia adotada pela EMBRATUR, composta por EBTs, Caravanas, Press-trips e Marca- 
Brasil, pode-se notar que o Instituto possui iniciativa e idéias interessantes, por outro lado, algumas considerações sobre os modelos adotados precisam ser apresentadas.

Mesmo com a expansão e instalação dos EBT's em outros países, a EMBRATUR (vinculada ao Ministério do Turismo) anunciou que pretende mudar a estrutura de seus escritórios de representação do Brasil no exterior. A mudança foi provocada pelo relatório da Controladoria Geral da União (CGU) sobre irregularidades que a EMBRATUR supostamente vem cometendo desde 2004 na contratação de escritórios sem licitação e pessoal sem concurso fora do país (CAZIAN, 2005).

A EMBRATUR se defendeu dizendo que vai manter o convênio com a Federação Brasileira de Convention \& Visitors Bureau (FBC\&VB) e mudou a estrutura dos escritórios. Esse novo modelo dos escritórios, que foi implantado no ano de 2006, mantém os mesmos objetivos, sendo mais eficazes, menos onerosos e adequados às orientações dos órgãos de controle (ALEXANDRI, 2005).

As Caravanas, assim como o Press-trips, são iniciativas de sucesso, pois a considerar que a questão da imagem que se faz depende não apenas de conhecimento do lugar, mas também de contato com o serviço, as ações facilitam sobremaneira o processo de conhecimento da imprensa, bem como de lideranças do turismo, de conhecer o turismo nacional.

Finalmente, a Marca-Brasil está bem fundamentada. Por outro lado, a pesquisa que foi realizada no exterior não está disponível para que todos que necessitam possam utilizar os dados e se atualizar com eles, além de ter sido realizada por uma consultoria internacional, ao invés de consultores nacionais, que teriam total capacidade e gabarito para tal, além de ficarem os recursos dentro do país. Outro ponto com relação à marca é que ela é utilizada apenas fora do país, e não há uma marca que identifique o Brasil internamente no que se refere ao turismo.

Nesse sentido, ainda há necessidade de pesquisa e desenvolvimento, não só para a MarcaBrasil, voltada para o interior do Brasil, como também de pesquisas voltadas para o conhecimento mais profundo do turista, e que estejam disponíveis. Não apenas disponíveis, mas auxiliando-os também a ler essas informações, divulgando seus resultados de maneira aplicada. Atualmente as pesquisas realizadas pela EMBRATUR são insuficientes para a necessidade do país. 


\section{Considerações Finais}

Este trabalho apresenta contribuições para o conhecimento do turismo internacional do país e do que já foi realizado com relação a sua imagem. A EMBRATUR, atual órgão responsável pela divulgação e promoção do turismo internacional, já esteve sobrecarregada com muitas outras atividades, antes de receber, como atribuição exclusiva, a promoção do turismo no exterior, o que dá ao Instituto um grande mérito por tudo o que já foi realizado.

Entende-se também que o estudo de caso proporciona ao aluno a possibilidade de entender o cenário atual e simular soluções, situando-o próximo ao que de fato os profissionais destas instituições tiveram de opção para realizar. Por isso, colocado como desafio em sala de aula, pode ser um recurso didático interessante.

Considerando que o turismo tem um mercado altamente competitivo e global, e que o turista é um consumidor mais exigente, sugere-se que, caso não encontre a estrutura que deseja para trabalhar em São Paulo, para relaxar nas praias nordestinas ou para vivenciar emoções diferentes na Amazônia, utilize qualquer outra opção no mundo, ao invés das nacionais. Atrair um cliente-turista é muito difícil, em função do enorme leque de opções existentes ao redor do planeta, considerando cada país como um possível destino, pois apenas assim já existem mais de 100 opções. Por isso, é importante haver investimentos no turismo nacional e na sua promoção internacional, seja através de parcerias ou alianças, envolvendo as Pequenas, Médias e Micro Empresas, comunidades no desenvolvimento e comercialização de produtos e serviços turísticos, além do apoio do Governo Federal através dos órgãos públicos responsáveis pela promoção do Turismo brasileiro interno e externo. É necessário também investir em infra-estrutura (transportes, hotéis, segurança, sinalização, etc), propaganda do país no exterior, qualificação, valorização e remuneração da mão-de-obra. Quadro que parece evidente, contudo, pouco trabalhado no Brasil.

Apesar da hospitalidade brasileira e das belezas naturais ajudarem o Brasil a ser promovido como destino turístico no exterior, é preciso elevar a qualidade dos serviços aos padrões internacionais. O destino Brasil precisa ganhar importância na mídia internacional, focando cada vez mais o país como um mercado importante, com uma economia e exportações em franco crescimento e, além de tudo isso, ser reconhecido como um país diverso culturalmente e altamente atraente para o turismo internacional. 
Para concluir, apresentar-se-á algumas sugestões das várias possíveis para trabalhos futuros. A realização de um acompanhamento longitudinal das ações aqui apresentadas para comparações do que ocorreu e de alguns desfechos como, por exemplo, o caso dos EBTs e do Projeto Caravana Brasil. Outra sugestão são estudos complementares aos trabalhos de pesquisa que são realizados pela EMBRATUR, assim como pelos que virão no Ministério do Turismo.

Ainda o trabalho de pesquisa para o desenvolvimento de uma marca consolidada para o público interno, assim como pesquisas sobre esse consumidor interno que sejam consolidadas com as pesquisas e anuários que a EMBRATUR possui hoje para a área de turismo. Finalmente, realizar um levantamento de como, e se, as estatísticas produzidas e divulgadas são compreendidas e aplicadas por aqueles que dela necessitam.

\section{Referências Bibliográficas}

ANDRADE, J. V. 2000. Turismo: fundamentos e dimensões. São Paulo: Ática.

ALEXANDRI, A. 2005. Irregularidades fazem a EMBRATUR mudar. [mensagem institucional]. Mensagem recebida por <amanda.leite@EMBRATUR.gov.br> em 04 nov.

ATHIA, G. 2004. Brasil quer atrair investimentos, mas esquece de cuidar da sua "marca-país". Publicação Eletrônica América Online, 12 jul. 2004. Disponível em: $<$ http://noticias.aol.com.br/negocios/industria/2004/07/0004.adp>. Acesso em: 03 out. 2005.

BENI, M. C. 2001. Análise estrutural do turismo. 8. ed. São Paulo: Senac.

BERKOWITZ, E.; KERIN, R.; HaRtley S.; RUDELIUS, W. 2004. Marketing. 6. ed. Rio de Janeiro: LTC.

BIGNAMI, R. 2002. A imagem do Brasil no turismo. São Paulo: Aleph.

BRASIL - Ministério do Turismo. S/D. Estatísticas básicas do turismo no Brasil. Disponível em: <http://www.turismo.gov.br/site/br/home/index.php>. Acesso em: 20 out. 2005.

BRASIL - Ministério do Turismo. 2003. Plano Nacional do Turismo. Brasília, 29 abr. 2003. Disponível em: <http://institucional.turismo.gov.br/mintur/contentobjects/dbfiles/170C1584-E07DD342-82C68965ADF6AF8F.arquivo.pdf>. Acesso em: 13 out. 2005.

BUSINESS GUIDE. 2004. EMBRATUR divulga ações para 2004 durante evento em São Paulo. Publicação Eletrônica, 23 mar. 2004. Disponível em: <http://www.businessguide.com.br/noticias /noticia_501.htm>. Acesso em 03 out. 2005.

CAZIAN, F. 2005. Irregularidades fazem a EMBRATUR mudar. Publicação Eletrônica Folha Online Dinheiro, 04 nov. 2005. Disponível em: <http://www1.folha.uol.com.br/folha/dinheiro/ ult91u102044.shtml >. Acesso em: 09 nov. 2005. 
CIAFFONE, A.; AZEDO, S. 2004. Mídia Segmentada vai Sobreviver à Internet, Projeta Especialista. Gazeta Mercantil, São Paulo, p. A-14, 28 ago.

CROMPTON, J. L. 1979. An assessment of the Imagem of Mexico as a Vacation Destination and the Influence of Geographical Location Upon that Image. Journal of Travel Research, v. 17, n.4, p. 18-23.

DIAS, K. A. 2005. Diversidade Cultural na Comunicação Visual: o caso EMBRATUR. Trabalho de Conclusão de Curso de Especialização. Centro de Excelência em Turismo. Universidade de Brasília.

EMBAIXADA DO BRASIL. S/D. Otawa. EMBRATUR tem agora Novo Foco. Disponível em: $<$ http://www.brasembottawa.org/prt/viagem_turismo>. Acesso em: 10 out. 2005.

EMBRATUR - Instituto Brasileiro de Turismo. S/Da. Contatos. Disponível em: < http://www.brasilnetwork.tur.br/Embratur/FaleConosco.do?method=preparaFaleConosco>. Acesso em: 6 abr. 2008.

EMBRATUR - Instituto Brasileiro de Turismo. S/Db. Dados \& Fatos: estudos e pesquisas. Disponível em: < http://www.braziltour.com/site/br/dados_fatos/conteudo/desembarque _int.php?in_secao=396>. Acesso em: 20 fev. 2007.

EMBRATUR - Instituto Brasileiro de Turismo. 2004. Estudo da demanda turística internacional 2003. Brasília: EMBRATUR.

EM QUESTÃO. 2005. Turismo no Brasil cresce acima da média mundial. Jornal Eletrônico Editado pela Subsecretaria de Comunicação Institucional da Secretaria-Geral da Presidência da República, n. 353, 8 set. 2005. Disponível em: <http://www.brasil.gov.br/emquestao/eq353.htm>. Acesso em 05out. 2005.

FARKAS, K. S/D. Plano aquarela vai nortear promoção internacional do Brasil nos próximos anos. Disponível em: <http://200.189.169.135/marcabrasil/conceito.pdf>. Acesso em: 20 out. 2005.

FORTES, I. 2005. Governo cria marca para promover produtos e serviços do Brasil no exterior. Folha Online, 18 fev. 2005. Disponível em: <http://www1.folha.uol.com.br/folha/dinheiro /ult91u93571.shtml>. Acesso em: 10 out. 2005.

IBGE - INSTITUTO BRASILEIRO DE GEOGRAFIA E ESTATÍSTICA. 2005. Dados de Desemprego relativos a setembro de 2005. Disponível em: <www.ibge.gov.br>. Acesso em: 30 out. 2005.

INDEC - INSTITUTO NACIONAL DE ESTADISTICA Y CENSOS. 2004. Turismo internacional. Mercosur y países seleccionados. Disponível em: < http://www.indec.mecon.ar/default.htm>. Acesso em: 20 fev. 2007.

KOTLER, P.; GERTNER, D. 2002. Country as brand, product and beyond: A place marketing and brand management perspective. Brand Management, v. 9, n. 4-5, p. 249-261.

KOTLER, P.; BOWEN, J.; MARKENS, J. 1999. Marketing for hospitality and tourism. 2. ed. Nova Jersey: Prentice Hall.

LEAL, S. 2004. A Imagem de Destinações Turísticas: um estudo de caso do Brasil na percepção de alunos baseados na Austrália. Retur, v. 2, n. 2, p. 1-8.

MARIANI, M. A. P. 2002. Percepção dos turistas e moradores do município de Bonito: o lugar, os sujeitos e o turismo. Turismo: Visão e Ação, v. 4, n. 11, p. 33-46.

MOWEN, J. C.; MINOR, M. S. 2003. Comportamento do consumidor. São Paulo: Prentice Hall 
PAIVA, M. G. M. V. 1995. Sociologia do turismo. Campinas: Papirus

PÉREZ-NEBRA, A. R. 2005. A imagem do Brasil no turismo. 2005. 167 f. Brasília, DF. Dissertação (Mestrado). Dissertação de mestrado apresentada ao Instituto de Psicologia da Universidade de Brasília como requisito parcial à obtenção do título de Mestre em Psicologia.

REZENDE-PARKER, A. M.; MORRISON, A. M. \& ISMAIL, J. A. 2003. Dazed and confused? An exploratory study of the image of Brazil as a travel destination. Journal of Vacation Marketing, v. 9, n. 3, p. 243-259.

ROSS, G. F. 2001. Psicologia do Turismo. São Paulo, SP: Contexto,

RUÃO, T.; FARHANGMER, M. 2000. A imagem da marca: análise das funções de representação e apelo no marketing das marcas: um estudo de caso. In: Seminário de Marketing Estratégico e Planejamento, I. 2000. Portugal. Acta do Seminário... Escola de Economia e Gestão, Universidade do Minho.

RUSCHMANN, D. 1990. Marketing turístico. Campinas, SP: Papirus.

SILVA, C. J. R. 2005. Marketing estratégico de lugares. In: TRIGO, L. G. G. et al. (Ed.). Análises regionais e globais do turismo brasileiro. São Paulo: Roca, p.81-93.

THOMAS, V. S/D. Cuidado com as Previsões. Grupo Banco Mundial. Disponível em: $<$ http://www.obancomundial.org/index.php/content/view_artigo/1991.html>. Acesso em: 08 de nov. de 2005.

TYBOUT, A. M.; STERNTHAL, B. 2001. Posicionamento de marca. In: Iacobucci, D. Os desafios do marketing. São Paulo: Editora Futura, Cap. 2.

Recebido em: 05/01/2007 (1 a versão) 25/02/2008 ( $2^{\text {a }}$ versão)

Aprovado em: 06/04/2008 